\title{
Revisión
}

\section{Discurso científico Twitter en el primer trimestre de pandemia en Ecuador}

Sofía Cabrera sofiai.cabrera国ute.edu.ec

Melissa Clavijo melissa.clavijo@oime.com.ec

Recibido: 15 de julio de 2020 | Aceptado: 11 de agosto de 2020

D0I: https://doi.org/DOl 10.18272/pd.v4i1.1882

Referencia de este artículo:

Cabrera, S., Clavijo, M. (2020). Discurso científico en Twitter en el primer trimestre de pandemia en Ecuador. \#PerDebate, volumen 4 (pp. 128-155). Quito: USFQ Press.

Melissa Clavijo es licenciada en Periodismo por la Universidad San

Francisco de Quito. Locutora y productora digital de radio Forever, también es investigadora del OIME. Inició su carrera profesional con pasantías en el Grupos Ekos y el programa Visión 360 de Ecuavisa.

Sofía Cabrera es candidata a doctora en Lógica y Filosofía de la Ciencia por la Universidad de Salamanca, España. Docente de Periodismo en la Universidad UTE. Coordinadora de la Red de divulgación KUNA Ecuador e integrante del Observatorio Interuniversitario de Medios Ecuatorianos (OIME). 


\section{Resumen}

Esta investigación identifica las cuentas de Twitter de reconocidos científicos ecuatorianos para hacer un análisis del discurso científico y contenido publicados, con el propósito de divulgar ciencia en esta red social. Se identificaron las temáticas abordadas por cada usuario durante el periodo de abril a junio de 2020, primer trimestre de la crisis sanitaria en Ecuador provocada por la pandemia de COVID-19. Mediante un estudio cuantitativo se toman en cuenta variables correspondientes a la plataforma digital como el uso de hashtags, menciones y material audiovisual. El análisis de contenido clasifica las publicaciones de los científicos con el fin de evaluar si estas cumplen con ejes esenciales de la divulgación científica como la verificación, la exposición y la argumentación de datos.

\section{Palabras clave}

opinión pública, científicos, discurso, Twitter, COVID-19

\section{Scientific speech on Twitter in the first quarter of the pandemic in Ecuador}

\section{Abstract}

This research identifies the Twitter accounts of renowned Ecuadorian scientists to make an analysis of scientific discourse and published content, with the purpose of sharing scientific information on this social network. It identifies the topics addressed by each user during the period from April to June 2020, the first quarter of the health crisis in Ecuador caused by the COVID-19 pandemic. Through a quantitative study, variables corresponding to the digital platform are taken into account, such as the use of hashtags, mentions, and audiovisual material. The content analysis classifies the publications of scientists in order to assess whether they comply with essential axes of scientific dissemination such as data verification, exposition, and argumentation.

\section{Keywords}

public opinion, scientists, discourse, Twitter, COVID-19 


\section{Introducción}

En la sociedad actual, analizar los discursos que circulan se ha constituido en una clara tendencia desde diferentes campos de las ciencias sociales (Santander, 2011), mucho más cuando esos discursos se viralizan con facilidad en las redes sociales, principal medio de comunicación masiva. Esto lleva a entender lo discursivo como un modo de acción.

Las redes sociales pueden definirse como una agrupación de actores, organizaciones y comunidades globales vinculadas a un conjunto de relaciones sociales simplificadas en un espacio atemporal, ahora mediado por las nuevas tecnologías (Muñoz y Argüelles Álvarez, 2010). En la actualidad, los individuos construyen diferentes realidades que les permite emitir, transmitir e interpretar mensajes ya no solo de forma tradicional, sino con el uso de las redes sociales, que fomentan la colaboración y el intercambio ágil de información.

Durante la pandemia de COVID-19, se fortaleció el consumo de información desde medios digitales y redes sociales, sobre todo porque la cuarentena aisló físicamente a las personas de sus diferentes rutinas, en las que compartían socialmente. Por lo que, actualmente, muchos grupos de la sociedad recurren a estas redes para mantenerse en contacto. Esta mediación digital, que no es lo mismo que la alfabetización digital, porque no todos los usuarios están capacitados para usarla, les permite seguir y comentar en tiempo real los acontecimientos de la pandemia de COVID-19, en el ámbito local y mundial. El acceso y producción de información en canales masivos como las redes sociales han generado la comunicación de hechos, opiniones profesionales y juicios personales.

De acuerdo con Del Alcázar Ponce (2019), se registraban un promedio de 13,8 millones de usuarios de Internet en Ecuador hasta diciembre de 2019, dato que se mantiene para el primer semestre del año 2020. En Ecuador hubo un claro aumento del uso de redes sociales para compartir información sobre la pandemia de COVID-19. Los medios digitales y las redes sociales se posicionan como la principal fuente de información, de acuerdo con datos de una encuesta aplicada por KUNA (2020) que tuvo el propósito de conocer cómo las ecuatorianas, los ecuatorianos y residentes en Ecuador obtienen información sobre la pandemia causada por la enfermedad de COVID-19 en el país.

En este contexto, Twitter es una de las redes sociales más vitales para la población durante la pandemia, ya que ha permitido la información inmediata de las últimas noticias y declaración de autoridades sobre la gestión y el manejo de la crisis sanitaria dentro y fuera del país. Esta herramienta aplica la 
teoría del compromiso público, permite a los usuarios tener conversaciones, formar comunidades, compartir contenido y construir relaciones (Smith, 2015).

Los mensajes de Twitter proponen un nuevo sistema de interacción comunicativa (Avendaño y Arrieta, 2018) debido a que esta red se diferencia de las otras porque requiere síntesis, claridad y puntualidad en el lenguaje, lo que se denominaría como economía del lenguaje. Ha marcado un performance propio para informar, denunciar, criticar, agredir, convencer y persuadir, básicamente un método generador de opinión pública. Twitter ha sido y sigue siendo un canal de gestores de opinión para comunicarse con la ciudadanía (Moreno, 2020).

Desde el inicio de la declaración de emergencia sanitaria en Ecuador, Twitter se convirtió en un importante canal para diferentes actores de la comunidad científica, quienes divulgaban sus conocimientos y percepciones sobre las primeras decisiones tomadas por el gobierno para la gestión de la pandemia. Poco a poco su interacción en esta red se hizo parte de su cotidianidad, y han consolidado un grupo de seguidores, interesados en mantener contacto directo con investigadoras e investigadores para recibir información científica. Involucrar al público a través de la comunicación científica se ha convertido en una actividad principal (Bowater y Yeoman, 2013), y el llamado a esta comunidad a ser más comprometidos con el público nunca ha sido más claro. Las redes sociales han presentado una oportunidad prometedora para hacer precisamente eso.

En este contexto, este artículo tiene como objetivo analizar la construcción de los discursos científicos de actores de la comunidad científica del Ecuador, para identificar su incidencia e impacto como gestores de información durante la pandemia de COVID-19 en el país.

\section{Metodología}

Para desarrollar este artículo, se aplicaron técnicas de investigación cuantitativa y cualitativa, por la posibilidad de tener resultados complementarios, ya que las primeras miden y las otras comprenden (Niño, 2011). Los dos enfoques permiten consolidar resultados para contextualizar el problema de estudio planteado.

\subsection{Herramientas cuantitativas}

Primero se seleccionaron cinco cuentas de Twitter de actores activos de la comunidad científica: tres mujeres y dos hombres. Las y los científicos seleccionados son investigadores de diferentes universidades del país y, durante la pandemia de COVID-19, se convirtieron en líderes de opinión. A continuación, se presenta la información biográfica de sus perfiles en Twitter: 
1. María Claudia Segovia. Bióloga de plantas. Investigadora de la Universidad de las Fuerzas Armadas (ESPE). Coordinadora de la Red Ecuatoriana de Mujeres Científicas REMCI.

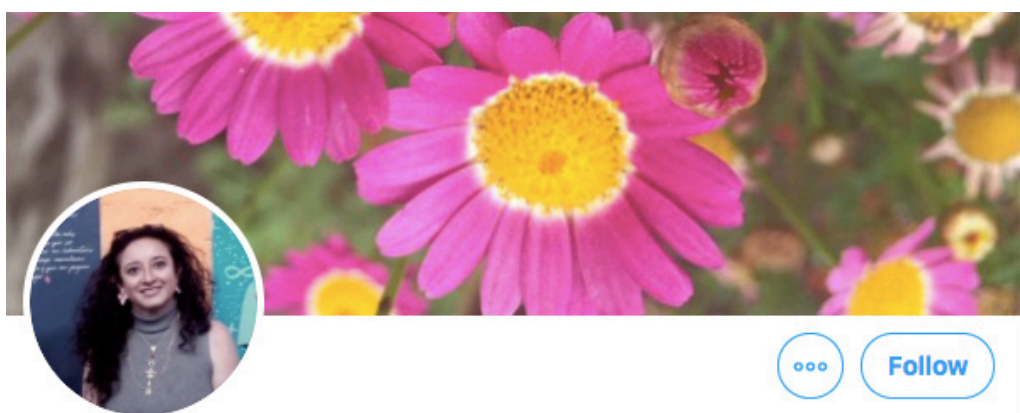

\section{María Claudia Segovia 을}

@mariacsegovia

\#PlantBiologist. Cofounder @CientificasEC Interested on \#AndeanConservation, \#ScienceEducation, \#Womeninscience, \#Ecuador

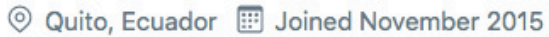
3,632 Following
4,474 Followers
Q Followed by Josselyn Pérez, KUNA, and 4 others you follow

2. Santiago Ron, Ph. D. Biología evolutiva. Profesor Principal de la Pontificia Universidad Católica del Ecuador. Curador del museo QCAZ. Miembro fundador Academia de Ciencias del Ecuador.

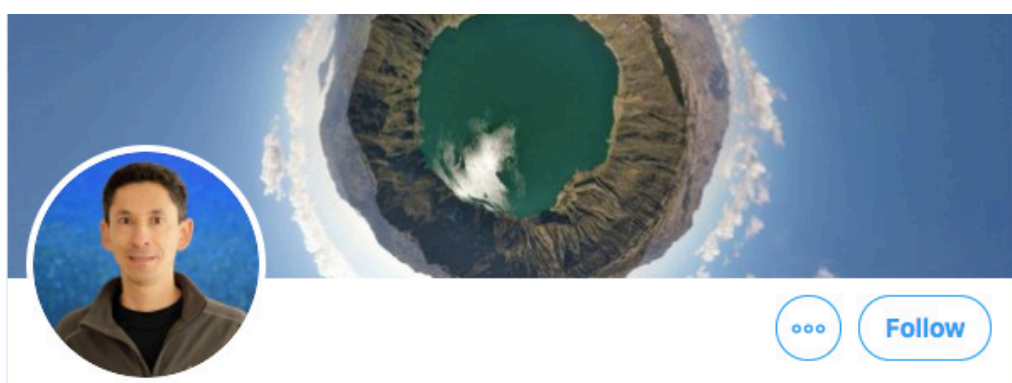

\section{Santi Ron}

@santiak

Ph.D. Biología Evolutiva. Profesor principal PUCE. Curador del museo QCAZ. Miembro fundador Academia de Ciencias del Ecuador. A, d ob Cuenta personal.

() Quito, -0.188010,-78.479507 \& orcid.org/0000-0001-6300...

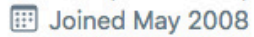
1,177 Following
8,797 Followers
(4) Followed by KUNA, Esteban Ortiz, and 3 others you follow 
3. Linda Guamán. Microbióloga. Trabajando en la ingeniería de bacterias Microbeth a través de SynBio y CRISPR CasDNA. Comunicadora científica en construcción. Actual asesora de la Secretaría de Salud del Municipio de Quito.

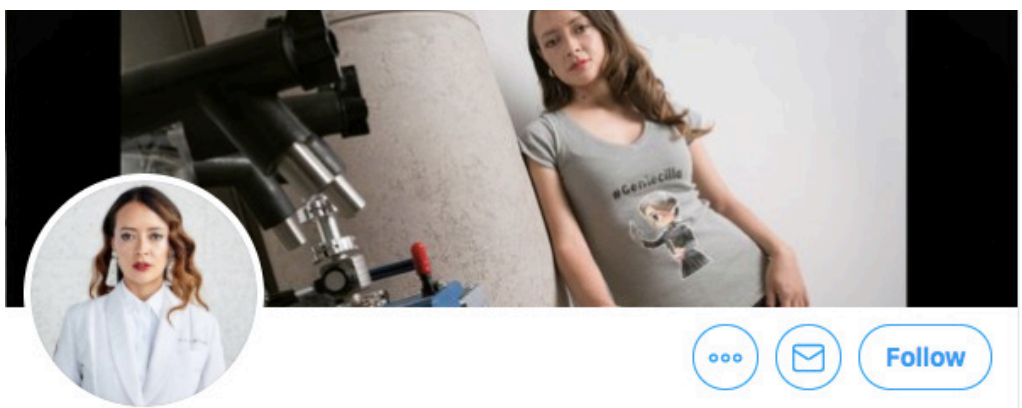

\section{Linda Guamán}

@lindaguaman

Microbiologist |Working on engineering bacteria through SynBio and CRISPR Cas ${ }^{\circ}$ | Science communicator in construction| In love of dogs and boxing|Tweets my own

() Quito $\mathcal{S}$ linkedin.com/in/lindag1 @ Born 1985 国 Joined August 2011

619 Following 14.3K Followers

Q. Followed by Josselyn Pérez, KUNA, and 6 others you follow

4. Esteban Ortiz. Médico Investigador. Docente de la Universidad de las Américas UDLA. Divulgador científico. Máster en Salud Pública y Salud Global. Ph. D. (c) en Biomedicina.

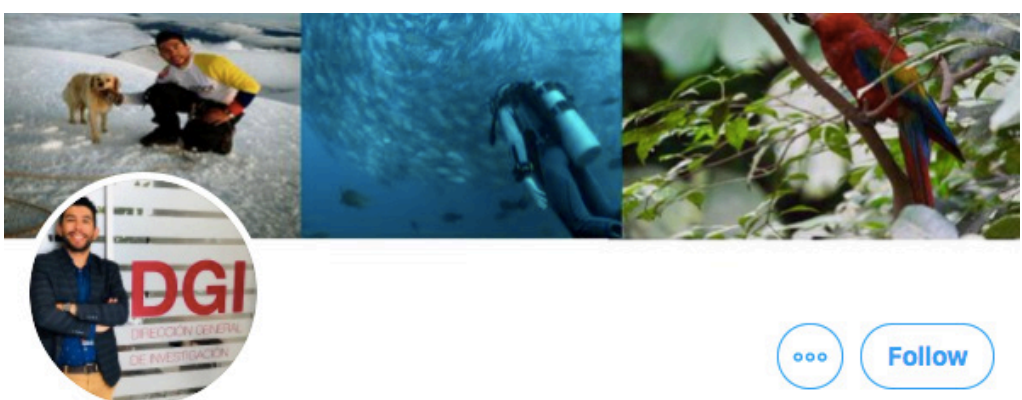

\section{Esteban Ortiz}

@EstebanOrtizMD

Médico Investigador \#DivulgadorCientifico \#MSc \#MPH \#PhD(c) \#salud \#SaludPublica \#OneHealth \#HighAltitude \#covid19 \#SocialDeterminants $f^{8}+5$

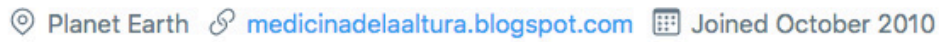

\section{3,963 Following $\mathbf{3 4 . 4 K}$ Followers}

B. Followed by KUNA, Melissa, and 3 others you follow 
5. Damaris Intriago. Máster en Medicina Molecular. Docente Investigadora de la Universidad Internacional SEK. Diplomado en Educación. Divulgadora científica.

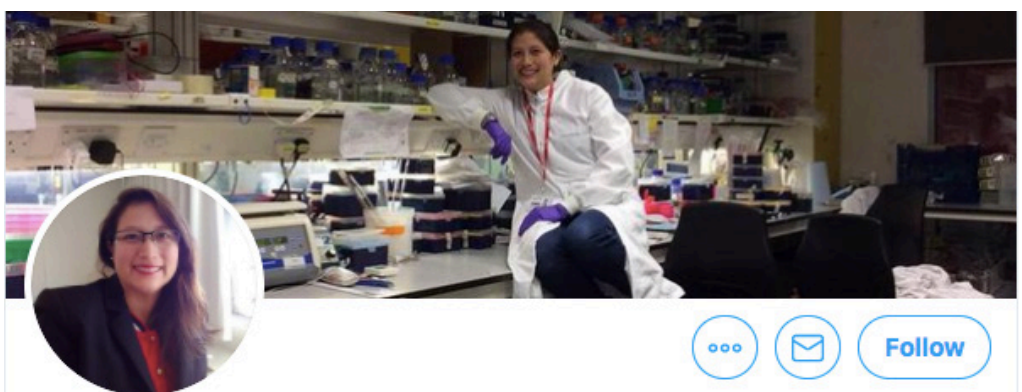

Dámaris Intriago

@DamarisIntriago

MSc Molecular Medicine - @imperialcollege Diploma in Education - @TecdeMonterrey I/ | \#SciComm @Cienciabajolupa |

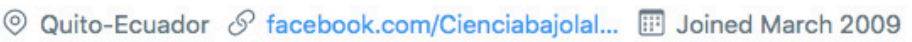

\section{$\mathbf{5 , 0 6 9}$ Following $\mathbf{5 , 7 0 2}$ Followers}

A) Followed by KUNA, PeriodismoUSFQ, and 2 others you follow

Las publicaciones de los usuarios se clasificaron en tres grandes ramas: temáticas, tipo de contenido y material de apoyo utilizado. Por medio de un análisis cuantitativo, se registraron los tweets de abril a junio de 2020 a través de la herramienta Twitonomy. Los especialistas fueron seleccionados por ser identificados, en la red social, como líderes de opinión referente a la crisis sanitaria que enfrentó Ecuador durante la pandemia de COVID-19. Se tomó en cuenta su número de seguidores y su perfil profesional, así como el uso de hashtags, palabras clave que se utilizan en redes sociales para etiquetar e identificar el contenido.

Utilizando la herramienta de análisis de tweets Twitonomy, se pudo cuantificar los promedios de tweets por día y la acumulación de likes y retweets. Esta información permitió ver el alcance de las cuentas y la relación con su público. También se analizó el promedio de hashtags y enlaces por cada tweet, así como la implementación de material de apoyo como enlaces, gráficos e infografías para sustentar las publicaciones.

\subsection{Herramientas cualitativas}

Para realizar el análisis cualitativo, se cuantificó y clasificó el tipo de contenido que compartieron las y los usuarios durante el mes de abril, el de mayor afectación de la crisis sanitaria en Ecuador por el pico alto de contagios y mortalidad, 
sobre todo en la ciudad costera de Guayaquil. Con el tweet de mayor impacto del mes de abril de cada usuario, se realizó un análisis desde la perspectiva lingüística, identificando deícticos, término derivado del griego que significa "indicar" o "mostrar", que remiten a los participantes y a las circunstancias de una determinada situación enunciativa (Avendaño y Arrieta, 2018), además se realizó un análisis del contexto en el que fueron publicados los tweets destacados de este mes. La aplicación de esta herramienta permitió identificar la forma en la que se posicionaron las y los usuarios científicos dentro de Twitter en los posteriores meses de la pandemia.

Finalmente se realizó una entrevista a las y los usuarios de las cuentas analizadas, para conocer su percepción sobre su interacción en Twitter, intereses, propuestas y manejo de información para divulgar y compartir durante la pandemia.

\section{Resultados y discusión}

A continuación, se identifican las cuentas de Twitter de las y los usuarios, y su número de seguidores hasta junio 2020.

\begin{tabular}{|c|c|c|}
\hline Científico & Usuario de Twitter & Seguidores \\
Esteban Ortiz & @EstebanOrtizMD & $28,5 \mathrm{mil}$ \\
Linda Guamán & @lindaguaman & $10,4 \mathrm{mil}$ \\
Santiago Ron & @satiak & 6315 \\
Damaris Intriago & @DamarisIntriago & 4753 \\
María Claudia Segovia & @mariacsegovia & 3922
\end{tabular}

Figura 1. Número de seguidores hasta el 15 de junio de los usuarios analizados.

Se registró el número de seguidores de cada cuenta el 15 de junio, fecha en la que inició la investigación. El científico con más seguidores es Esteban Ortiz con 28,5 mil. Linda Guamán tiene 10,4 mil seguidores, Santiago Ron posee 6315 y Damaris Intriago 4753. María Claudia Segovia es quien tiene menor cantidad de adeptos en comparación con Ortiz.

\subsection{Análisis lingüístico del discurso científico}

Para este análisis se utiliza la teoría de la enunciación, que establece que los actos de habla tienen lugar a través de los enunciados y en la puesta en escena alcanzan su mayor relevancia, por lo tanto, se encarga de estudiar la relación entre el enunciado y su contexto, y, por ende, su comprensión en el público (Avendaño y Arrieta, 2018).

Para Jakobson (1957), citado por Avendaño y Arrieta (2018), los shifters, deícticos o conmutadores, son símbolos-índices que remiten al mensaje e implican 
una referencia al proceso de enunciación. Vale aclarar que las marcas lingüísticas (pronombres, adverbios, desinencias verbales, etc.) constituyen deixis siempre que estén en relación con el sujeto de la enunciación. Los deícticos se dividen en persona, tiempo y espacio. Los de persona utilizan pronombres personales, posesivos y demostrativos, los de tiempo están relacionados con los adverbios de tiempo y, finalmente, los de espacio manifiestan adverbios de lugar.

Siguiendo esta propuesta, se seleccionó el tweet más destacado por número de likes y retweets del mes de abril de cada usuario analizado. El tweet de Linda Guamán contó con 994 retweets y 1,1 mil likes; el de Esteban Ortiz, 1,2 mil retweets y 1,9 mil likes; el de Santiago Ron, 1,6 mil retweets y 1,4 mil likes; el de Damaris Intriago, 641 retweets y 869 likes; y, por último, el tweet de María Claudia Segovia, 34 retweets y 55 likes.

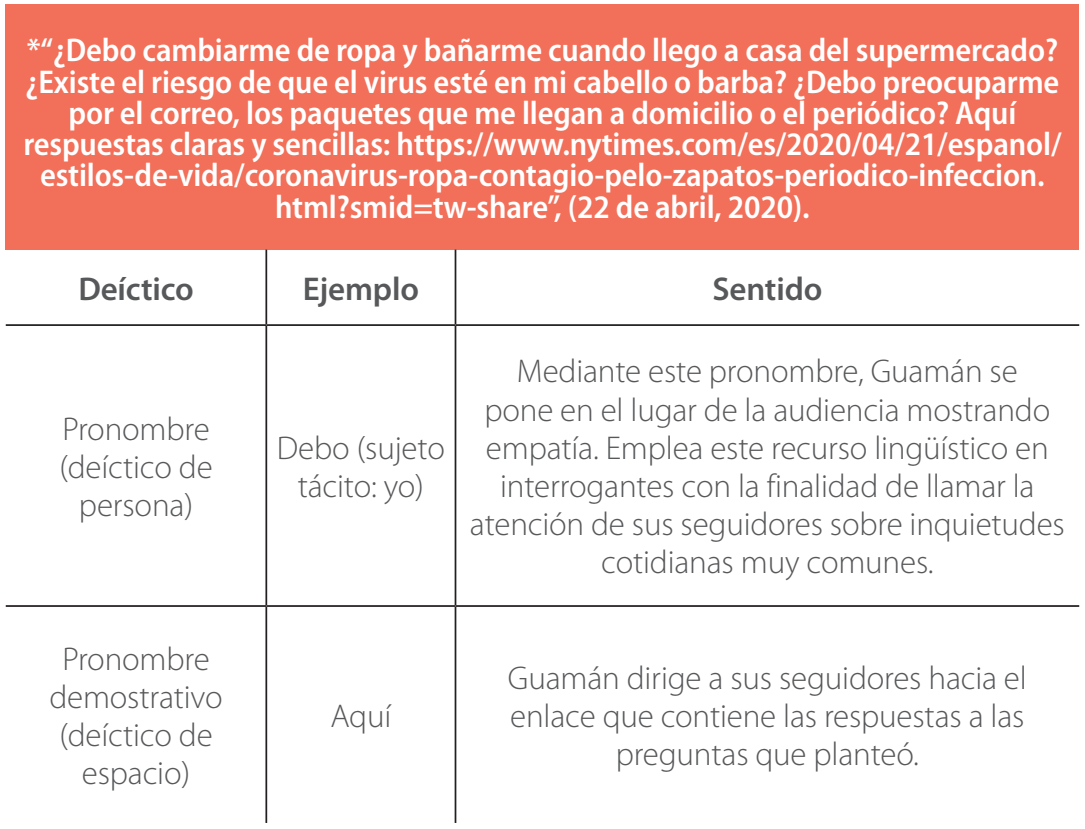

Figura 2. Tweet 1 * destacado de Linda Guamán en abril de 2020.

El tweet de Linda Guamán identifica claramente el interés de la enunciante en generar empatía con sus seguidores, durante el momento de crisis más fuerte de la pandemia en Ecuador, en el que se tenían pocas certezas sobre el nivel de propagación y contagio del virus. Evidentemente se nota el lenguaje divulgativo de la investigadora para utilizar preguntas retóricas con el propósito de compartir inquietudes cotidianas que iban surgiendo en torno a la pandemia. 
* "En relación a la cantidad de test de \#covid19 realizados en el Ecuador he visto mucha desinformación y politiquería alrededor de este tema. NO Trabajo para el Gob, les he sido muy crítico, pero es mi obligación ofrecer datos. Ustedes saquen su conclusión. Abro Hilo 1/10", (4 de abril, 2020).

\begin{tabular}{c|c|c} 
Deíctico & Ejemplo & Sentido \\
\hline $\begin{array}{c}\text { Pronombre } \\
\text { (deíctico de } \\
\text { persona) }\end{array}$ & Ustedes & $\begin{array}{c}\text { Ortiz le habla directamente a su comunidad de } \\
\text { seguidores para que verifiquen la información } \\
\text { que publica en su perfil. Realiza una } \\
\text { introducción respecto al flujo de información } \\
\text { en la red social, su postura política y aclaración } \\
\text { de no tener vínculo laboral con el Gobierno. }\end{array}$
\end{tabular}

Figura 3. Tweet $2^{*}$ destacado de Esteban Ortiz en abril de 2020.

El investigador Esteban Ortiz en su tweet destacado realiza una fuerte aclaración en torno a su postura política, identificando una posición como científico e investigador, e incita a su comunidad de seguidores a contrastar toda la información que se recibe en redes sociales. Twitter es una red con una fuerte tendencia política (Moreno, 2020), por lo que las y los seguidores siempre se identifican con la formación social (cultura, política, ideología) del enunciante al que siguen. En este caso, por esta razón el investigador Ortiz plantea un hilo de varios tweets para explicar esta información sobre los tests para diagnóstico de COVID-19 que considera importante que conozcan sus públicos.

* No quisiera alarmar, pero la situación de \#Covid19Ec en Ecuador es muy preocupante. @Lenin @mariapaularomo @DrJuanCZevallos Acabo de obtener los promedios quincenales del \% de tests positivos en marzo y abril para 84 países. Este es el resultado... (HILO largo)", (25 de abril, 2020).

\begin{tabular}{c|c|c} 
Deíctico & Ejemplo & Sentido \\
\hline $\begin{array}{c}\text { Desinencias } \\
\text { verbales (deíctico } \\
\text { de tiempo) }\end{array}$ & $\begin{array}{c}\text { Acabo de } \\
\text { obtener }\end{array}$ & $\begin{array}{c}\text { Ron utiliza el verbo conjugado en el tiempo } \\
\text { presente para reafirmar su postura sobre los } \\
\text { datos presentados en relación con pruebas } \\
\text { de detección de COVID-19y porcentaje de } \\
\text { positividad en Ecuador. }\end{array}$
\end{tabular}

Figura 4. Tweet $3^{*}$ destacado de Santiago Ron en abril de 2020.

En el caso del tweet más destacado del científico Santiago Ron, se evidencia una clara crítica al manejo de la gestión, en relación con los datos sobre porcentajes de tests positivos entre marzo y abril. Desde el inicio de la pandemia, este investigador se ha convertido en un actor importante en la red, por su seguimiento a la crisis con datos estadísticos que muestran el avance de la pandemia en Ecuador. Para Santiago Ron (2020), "uno de los principales problemas que hay en la actualidad es que uno encuentra una gran cantidad de informa- 
ción. Pero, si esa información no va acompañada de las fuentes es muy difícil saber si es algo confiable o no", por este motivo este investigador se ha enfocado en dar información sobre datos del estado de la pandemia en Ecuador, analizando número de casos, tests positivos e índices de mortalidad.

\begin{tabular}{|c|c|c|}
\hline Me $n$ & $\begin{array}{r}\text { *Ministro d } \\
\text { el secuencia } \\
\text { R: Se } \\
\text { Se requiere e } \\
\text { R: Lo: } \\
\text { b! No sabe qL }\end{array}$ & $\begin{array}{l}\text { Salud en cadena nacional: } \\
\text { lor automatizado para realizar las pruebas de } \\
\text { diagnóstico". } \\
\text { ama termociclador. } \\
\text { traer el RNA celular del virus". } \\
\text { virus no son células. } \\
\text { es un virus! } \Theta^{\prime \prime} \text { ( (13 de abril, 2020). }\end{array}$ \\
\hline Deíctico & Ejemplo & Sentido \\
\hline $\begin{array}{c}\text { Pronombre } \\
\text { (deícticos de } \\
\text { persona) }\end{array}$ & me (átono) & $\begin{array}{l}\text { Intriago se plantea a sí misma como receptora } \\
\text { de la información comunicada por el ministro } \\
\text { de Salud Juan Carlos Zevallos. Procede a } \\
\text { responder los alegatos que considera erróneos } \\
\text { y expone sus sentimientos hacia ello. }\end{array}$ \\
\hline
\end{tabular}

Figura 5. Tweet $4^{*}$ destacado de Damaris Intriago en abril de 2020.

Por otro lado, el tweet destacado de Damaris Intriago utiliza un lenguaje irónico para cuestionar las expresiones realizadas por el ministro de Salud, de esta forma se evidencia una postura cuestionadora sobre sus conocimientos sobre procesos de testeo de COVID-19. Su tweet tiene un fuerte impacto entre sus seguidores por la forma en la que lo manifiesta, lo que destaca la importancia del uso adecuado del lenguaje científico por parte del principal gestor de la crisis sanitaria en el país.

*"Por qué debemos incluir a mujeres en los procesos de respuesta del \#COVID19 ? @CientificasEC @KunaEcuador @RedlnvestChile @olgabarbosa @lindaguaman @EstebanOrtizMD https://news.trust.org/item/20200401090723-319sb", (5 de abril, 2020).

\begin{tabular}{c|c|c} 
Deíctico & Ejemplo & Sentido \\
\hline $\begin{array}{c}\text { Desinencias } \\
\text { verbales (deícticos } \\
\text { de persona / } \\
\text { deícticos de } \\
\text { tiempo) }\end{array}$ & $\begin{array}{c}\text { debemos } \\
\text { (sujeto tácito: } \\
\text { nosotros) }\end{array}$ & $\begin{array}{c}\text { Segovia involucra no solo a sus simpatizantes } \\
\text { sino a cuentas de otros usuarios con el } \\
\text { pronombre a disposición. Menciona a } \\
\text { organizaciones y personas naturales. La } \\
\text { conjugación en tiempo presente responde a la } \\
\text { acción inmediata que le exige a los enunciatarios. }\end{array}$
\end{tabular}

Figura 6. Tweet 5* destacado de María Claudia Segovia en abril de 2020. 
Finalmente, el tweet de María Claudia Segovia presenta su marcada postura activista de género en la ciencia. Es enfática en incluir voces de científicas ecuatorianas en los procesos de respuesta de COVID-19. La investigadora realiza su afirmación utilizando un enlace sobre esta temática. Segovia (2020) menciona: "Yo utilizo muchos links porque lo que trato de hacer es pasar la información del inglés al español para generar conexión con la audiencia. Tal vez en inglés no le prestarían mucha atención".

En este análisis lingüístico del discurso científico se muestra una relación contractual entre las y los enunciadores, actores de la comunidad científica. Verón (1985), citado por Avendaño y Arrieta (2018), sostiene que el contrato de lectura no reside solamente en los contenidos, sino en los contenidos que se toman desde quien habla (enunciador) y desde dónde se le propone un lugar al que en este caso lee el tweet del enunciatario. Los tweets destacados de abril de las y los científicos analizados muestran evidentemente su interés por generar interacción entre sus seguidores, se trasladan desde sus marcos de referencia y formación social al contexto del público para divulgar conocimientos que consideran necesarios colocar en este espacio de construcción de la opinión pública, para combatir la información falsa de redes sociales, politización y desconocimiento.

\subsection{Análisis de contexto}

Por otro lado, se describe el contexto en el que se presenta cada uno de los tweets destacados. El contexto se define en términos de modelos contextuales: no es la situación social, en la que se incluyen los participantes, la que influencia directamente la interpretación del discurso (Van Dijk, 1999), sino la construcción subjetiva de un modelo mental del contexto determinada por la referencialidad de los públicos para interpretar el discurso científico de las y los actores en Twitter.

La credibilidad es una cualidad que el público perceptor asigna a los hablantes o a los escritores, sobre la base de conocimiento socialmente compartido y de actitudes acerca de grupos y roles sociales (Van Dijk, 1999). En el caso de esta investigación el contexto está determinado por la incertidumbre de un virus nuevo, los sentimientos que genera y la falta de cultura científica del público perceptor, usuarios de Twitter, que entregan credibilidad a las y los investigadores que empiezan a divulgar en sus redes sociales.

La situación, los papeles comunicativos y sociales del público perceptor, las relaciones entre ellos (conflicto, dominio y cooperación), el escenario (espacio-tiempo) y las creencias también son rasgos de los modelos subjetivos de contexto que controlan la influencia del discurso (Van Dijk, 1999). El siguiente cuadro muestra el contexto de cada uno de los tweets destacados de la comunidad científica, que obtuvieron gran impacto entre la audiencia de Twitter. 


\begin{tabular}{|c|c|c|}
\hline Tweets & $\begin{array}{l}\text { Contexto situacional: } \\
\text { descripción de la realidad } \\
\text { sociopolítica }\end{array}$ & $\begin{array}{l}\text { Sentido de las } \\
\text { implicaturas } \\
\text { particularizadas }\end{array}$ \\
\hline $\begin{array}{l}\text { "¿Debo cambiarme } \\
\text { de ropa y bañarme } \\
\text { cuando llego a casa } \\
\text { del supermercado? } \\
\text { ¿Existe el riesgo de } \\
\text { que el virus esté en mi } \\
\text { cabello o barba? ¿Debo } \\
\text { preocuparme por el } \\
\text { correo, los paquetes que } \\
\text { me llegan a domicilio } \\
\text { o el periódico? Aquí } \\
\text { respuestas claras } \\
\text { y sencillas: https:// } \\
\text { www.nytimes.com/ } \\
\text { es/2020/04/21/ } \\
\text { espanol/estilos-de-vida/ } \\
\text { coronavirus-ropa- } \\
\text { contagio-pelo-zapatos- } \\
\text { periodico-infeccion. } \\
\text { html?smid=tw-share", } \\
\text { (22 de abril, 2020). }\end{array}$ & $\begin{array}{c}\text { Desinformación respecto } \\
\text { a medidas de seguridad } \\
\text { durante la pandemia. Las } \\
\text { primeras investigaciones } \\
\text { todavía no identificaban los } \\
\text { medios de propagación del } \\
\text { virus. } \\
\text { Viralización de contenidos } \\
\text { falsos sin sustentación } \\
\text { científica. } \\
\text { Cambio de ministro de } \\
\text { Salud, críticas al manejo de la } \\
\text { gestión. } \\
\text { Grave impacto de la crisis } \\
\text { sanitaria en Guayaquil, } \\
\text { ciudad costera más grande } \\
\text { del Ecuador de acuerdo a } \\
\text { la información emitida por } \\
\text { el Comité de Operaciones } \\
\text { Especiales COE. }\end{array}$ & $\begin{array}{l}\text { El contexto del tweet de } \\
\text { Guamán corresponde } \\
\text { a la cantidad de } \\
\text { recomendaciones que } \\
\text { circulaban en redes } \\
\text { sociales y en medios } \\
\text { de comunicación } \\
\text { sobre las medidas } \\
\text { de seguridad que se } \\
\text { podrían implementar } \\
\text { en casa. Especialmente, } \\
\text { sobre la permanencia } \\
\text { del virus en objetos o } \\
\text { partes del cuerpo. Con } \\
\text { las preguntas, Guamán } \\
\text { busca aplicar una } \\
\text { retórica para acercarse } \\
\text { a la cotidianidad de la } \\
\text { ciudadanía. }\end{array}$ \\
\hline $\begin{array}{l}\text { "En relación a la } \\
\text { cantidad de test de } \\
\text { \#covid19 realizados } \\
\text { en el Ecuador he visto } \\
\text { mucha desinformación } \\
\text { y politiquería alrededor } \\
\text { de este tema. NO } \\
\text { Trabajo para el Gob, les } \\
\text { he sido muy crítico, pero } \\
\text { es mi obligación ofrecer } \\
\text { datos. Ustedes saquen } \\
\text { su conclusión. Abro Hilo } \\
\text { 1/10", (4 de abril, 2020). }\end{array}$ & $\begin{array}{l}\text { Fuertes críticas al manejo } \\
\text { gubernamental de la crisis } \\
\text { sanitaria respecto a la } \\
\text { realización de pruebas de } \\
\text { COVID-19. }\end{array}$ & $\begin{array}{l}\text { Hasta el } 4 \text { de abril, se } \\
\text { habían registrado } 3465 \\
\text { casos confirmados en } \\
\text { Ecuador de acuerdo al } \\
\text { Ministerio de Salud. Ortiz } \\
\text { expuso una serie de } \\
\text { datos sobre la compra } \\
\text { de pruebas por el } \\
\text { gobierno ecuatoriano. } \\
\text { La aclaración de su } \\
\text { lineamiento político } \\
\text { se debe a que la } \\
\text { información que brindó } \\
\text { en ese hilo supone una } \\
\text { percepción positiva } \\
\text { sobre el manejo de la } \\
\text { gestión sanitaria de las } \\
\text { autoridades. }\end{array}$ \\
\hline
\end{tabular}




\begin{tabular}{|c|c|c|}
\hline Tweets & $\begin{array}{l}\text { Contexto situacional: } \\
\text { descripción de la realidad } \\
\text { sociopolítica }\end{array}$ & $\begin{array}{l}\text { Sentido de las } \\
\text { implicaturas } \\
\text { particularizadas }\end{array}$ \\
\hline $\begin{array}{l}\text { "No quisiera alarmar } \\
\text { pero la situación de } \\
\text { \#Covid19Ec en Ecuador } \\
\text { es muy preocupante. @ } \\
\text { Lenin @mariapaularomo } \\
\text { @DrJuanCZevallos } \\
\text { Acabo de obtener los } \\
\text { promedios quincenales } \\
\text { del \% de tests positivos } \\
\text { en marzo y abril para } \\
84 \text { países. Este es el } \\
\text { resultado... (HILO largo)", } \\
\text { (25 de abril, 2020). }\end{array}$ & $\begin{array}{c}\text { Nueva etapa de reglas } \\
\text { dispuestas por el Gobierno. } \\
\text { Críticas constantes al manejo } \\
\text { de datos estadísticos para } \\
\text { representar positividad y } \\
\text { mortalidad. }\end{array}$ & $\begin{array}{c}\text { El } 24 \text { de abril de } 2020, \\
\text { la ministra de Gobierno } \\
\text { María Paula Romo } \\
\text { anunció que el } 4 \text { de } \\
\text { mayo se empezaría una } \\
\text { nueva etapa, la nueva } \\
\text { normalidad. Este tweet se } \\
\text { refiere a esta decisión y } \\
\text { manejo gubernamental } \\
\text { de la crisis sanitaria } \\
\text { respecto a la realización } \\
\text { de pruebas para la } \\
\text { detección de COVID-19. } \\
\text { Los datos que expone } \\
\text { Santiago Ron son una } \\
\text { comparación con la cifra } \\
\text { de positividad de otros } \\
\text { países de América Latina.. }\end{array}$ \\
\hline $\begin{array}{l}\text { *"Ministro de Salud en } \\
\text { cadena nacional: } \\
\text {-"Ya tenemos listo } \\
\text { el secuenciador } \\
\text { automatizado para } \\
\text { realizar las pruebas de } \\
\text { diagnóstico". } \\
\text { R: Se llama } \\
\text { termociclador. } \\
\text {-"Se requiere extraer el } \\
\text { RNA celular del virus". } \\
\text { R: Los virus no son } \\
\text { células. } \\
\text { Me mató! No sabe que } \\
\text { es un virus! --", (13 de } \\
\text { abril, 2020). }\end{array}$ & $\begin{array}{c}\text { Constantes declaraciones del } \\
\text { ministro de Salud en medios } \\
\text { de comunicación para } \\
\text { explicar el proceso para la } \\
\text { detección de pruebas PCR. } \\
\\
\text { Uso de terminología } \\
\text { científica por parte del } \\
\text { ministro de Salud en las } \\
\text { cadenas nacionales. }\end{array}$ & $\begin{array}{l}\text { Intriago critica y corrige } \\
\text { al ministro de Salud } \\
\text { Juan Carlos Zevallos, } \\
\text { nombrado después de } \\
\text { la renuncia de Catalina } \\
\text { Andramuño. Para el } 13 \\
\text { de abril se registraron } \\
7529 \text { contagiados y } 355 \\
\text { fallecidos. Se evidencia } \\
\text { una fuerte crítica al } \\
\text { manejo de conceptos } \\
\text { técnicos por parte de la } \\
\text { autoridad. }\end{array}$ \\
\hline $\begin{array}{l}\text { "Por qué debemos } \\
\text { incluir a mujeres en los } \\
\text { procesos de respuesta } \\
\text { del \#COVOD19? @ } \\
\text { CientificasEC @ } \\
\text { KunaEcuador @ } \\
\text { RedlnvestChile @ } \\
\text { olgabarbosa @ } \\
\text { lindaguaman @ } \\
\text { EstebanOrtizMD } \\
\text { https://news.trust.org/ } \\
\text { item/20200401090723- } \\
\text { 319sb",(5 de abril, 2020). }\end{array}$ & $\begin{array}{c}\text { Falta de inclusión de mujeres } \\
\text { en asesorías técnicas, } \\
\text { entrevistas en medios } \\
\text { masivos y eventos públicos } \\
\text { para abordar el tema de la } \\
\text { pandemia. } \\
\text { La Red Ecuatoriana de } \\
\text { Mujeres en la Ciencia (REMCl) } \\
\text { trabaja constantemente } \\
\text { para evidenciar el trabajo } \\
\text { de mujeres en la ciencia de } \\
\text { Ecuador. }\end{array}$ & $\begin{array}{l}\text { El contexto de la pandemia } \\
\text { evidenció la fuerte } \\
\text { presencia de científicos } \\
\text { en la opinión pública. Sin } \\
\text { embargo, Segovia hace } \\
\text { referencia a la inclusividad } \\
\text { para invitar a científicas a } \\
\text { estos espacios. Etiqueta } \\
\text { a usuarios de actores } \\
\text { e instituciones que } \\
\text { fortalecen la paridad de } \\
\text { género en el discurso } \\
\text { científico. }\end{array}$ \\
\hline
\end{tabular}

Figura 7. Análisis contextual del tweet destacado de cada científico. 
El contexto en el que se destacan los tweets antes mencionados evidencia el interés que tenía el público de Twitter por recibir información científica contrastada y en un lenguaje común sobre el coronavirus, el desarrollo de la ciencia y el impacto en su cotidianidad. Esta situación fue identificada por diferentes actores sociales de la comunidad científica, quienes decidieron activarse en esta red social para compartir sus conocimientos desde un enfoque divulgativo.

\subsection{Análisis de contenido}

Utilizando la herramienta de búsqueda avanzada de Twitter, se analizaron todos los tweets escritos por las y los científicos seleccionados en esta investigación. Primero se analizaron los tipos de contenidos determinados por una categorización de la información más abordada durante el mes. En un segundo momento, se identifica el material de apoyo utilizado para conceptualizar los discursos compartidos en sus tweets.

\subsubsection{Tipo de contenido}

Datos científicos

Debate tendencia en redes

Análisis de curvas

Testimonio
Noticias

Evidencia científica Correlación de curvas

Encuesta
Opinión

Correlación de cifras

Informe

Linda Guamán

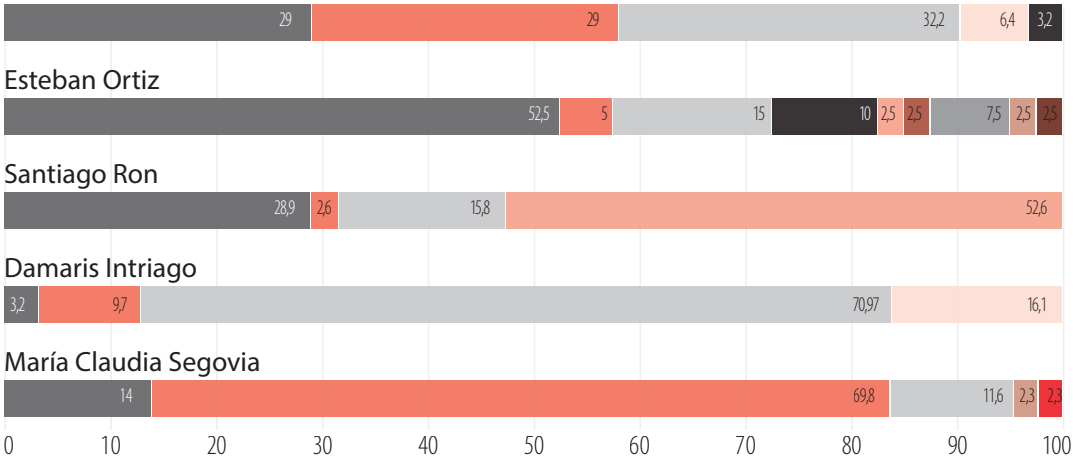

Figura 8. Tweets de Linda Guamán, Esteban Ortiz, Santiago Ron, Damaris Intriago y María Claudia Segovia en abril de 2020 clasificados por tipo de contenido.

Linda Guamán

Durante el mes de abril, los tweets de Linda Guamán se clasificaron con un $32,3 \%$ de opinión, $29 \%$ datos científicos, $29 \%$ noticias, $6,5 \%$ debates sobre las tendencias en la red social y 3,2\% evidencia científica. El dato de opinión refleja las fuertes críticas desde la comunidad científica al manejo de la gestión sanitaria en Ecuador. La investigadora se presenta en la red social con una marcada postura ante las políticas del Gobierno, e identifica un modelo propio 
para compartir datos científicos y noticias de interés del público de Twitter. Como dice Revuelta (2020), de la noche a la mañana, la máquina de la ciencia se ha expuesto ante el público con una omnipresencia aplastante llevando a científicas y científicos a la arena pública, lo que sustenta la posición mediática asumida por la investigadora Guamán.

Esteban Ortiz

El 52,5\% de las publicaciones de Esteban Ortiz en el mes de abril 2020 fueron datos. Sus tweets se clasificaron de la siguiente forma: opinión (15\%), evidencia científica (10\%), correlación de curvas (7,5\%), noticias de medios nacionales e internacionales (5\%), informes (2,5\%), testimonios (2,5\%), análisis de curvas ( $2.5 \%$ y correlación de cifras (2,5\%). De acuerdo con estas cifras, el investigador Ortiz se va posicionando con el público de Twitter por los datos científicos que empieza a publicar sobre la pandemia, tomando en cuenta que su posición se manifiesta dentro de un contexto de constante críticas al manejo y publicación de datos sobre positividad y mortalidad en el país. Para Ortiz (2020), Twitter permite elevar la voz científica y visibilizar problemas desde la ciencia, las personas buscan datos, pero también el contexto científico de lo que leen. Aunque el porcentaje de opinión es bajo, Ortiz mantiene una postura política e ideológica en redes, los contenidos que más comparte están relacionados con fortalecer su trabajo como actor de la opinión pública y las consecuencias positivas y negativas de esta acción.

\section{Santiago Ron}

El $52.6 \%$ de los tweets de Santiago Ron fue correlación de cifras. El $28.9 \%$ datos científicos, el $15.8 \%$ fue opinión y el $2.6 \%$ fue noticias de medios de comunicación. La pandemia de COVID-19 se desenvuelve en un panorama de hallazgos científicos, hechos e incertidumbres que cambian rápidamente (Dietram y Scheufele, 2020), por este motivo es importante el trabajo que desarrollan científicos y científicas para contextualizar datos, cifras y conceptos científicos sobre la temática. En el caso del investigador Ron se evidencia su interés por presentar cifras sobre positividad y mortalidad de COVID-19 en Ecuador, para contrarrestar las oficiales presentadas por el Ministerio de Salud. Santiago Ron (2020) manifiesta que la comunicación científica en Twitter debe regirse a los mismos estándares que el de una publicación científica, una adecuada citación es imprescindible para una mejor recepción del mensaje.

\section{Damaris Intriago}

El $71 \%$ de los tweets de Damaris Intriago durante el mes de abril fue clasificado como opinión. El $16.1 \%$ corresponde a debate sobre tendencias en la red social, el 9,7 \% a noticias y el 3.2 a datos científicos. El porcentaje de los tweets de opinión de la investigadora demuestran su notoria posición como gestora de opinión pública, dentro de un contexto de fuertes críticas a las 
autoridades sobre el manejo de la pandemia en Ecuador. Las herramientas digitales crean grupos de pertenencia para condicionar conductas (Alonso González, 2016), crean corrientes de opinión ampliamente aceptadas, y ello debido a dos mecanismos convergentes enunciados por Carl Sunstein (2009): el efecto cascada y la polarización de grupos. El efecto cascada se refuerza en la capacidad de expandir el mensaje a más personas, con el propósito de que los demás no puedan resistirse, en este caso, la información sobre la crisis del coronavirus y la gestión sanitaria del gobierno del Ecuador. Por otro lado, la polarización es una asimilación tendenciosa de la información, proviene de usuarios con intereses compartidos. En el caso de Intriago se evidencia el impacto de sus opiniones desde su posición como científica, lo que genera más impacto en sus usuarios seguidores, al ser Twitter una red eminentemente política (Moreno, 2020). Los usuarios se consolidan como generadores de contenido y de relatos que abarcan todas las temáticas de la actualidad (Guerrero- Pico y Scolari, 2016).

\section{Claudia Segovia}

El contenido de María Claudia Segovia se basa primordialmente en noticias de medios nacionales o internacionales (69,8\%). El $14 \%$ es de datos científicos, el 11,6 \% opinión, el 2,3\% informes y el 2,3\% encuestas de Twitter. La investigadora tiende a trabajar desde el principal esfuerzo del divulgador científico: buscar la mejor forma de explicar el hecho para acercarlo al lector (De Vicente Domínez y Cea Esteruelas, 2019). La investigadora identifica el potencial de Twitter para convertirse en una nueva fuente de información y una poderosa herramienta para los periodistas (González Bustamante, 2015). Se puede analizar el efecto cascada (Sunstein, 2009) desde su interés por replicar información científica para que llegue con mayor impacto en los usuarios de esta red social.

Para Jack Dorsey, creador de Twitter, esta red social es una herramienta de comunicación; es como la electricidad, uno puede utilizarla como quiera, favorece a la democracia directa, es una revolución social y cultural que acerca a los ciudadanos al poder (citado en Fernández y Paniagua, 2012, p. 42). En el caso de esta investigación, se evidencia que Twitter se convirtió en una red social importante en Ecuador para hablar de ciencia, en un espacio eminentemente político (Moreno, 2020) y también para posicionar a científicos y científicas como líderes de opinión desde el inicio de la pandemia en el país. El interés por divulgar ciencia por parte de la comunidad científica también es relevante, porque han identificado un lenguaje idóneo para generar cercanías con las y los usuarios que les siguen; básicamente las y los científicos que interactúan activamente con el público tienden a ser receptivos, y consideran que su público está informado y quiere aprender más sobre ciencia (Smith, 2015). 


\subsubsection{Material de apoyo}

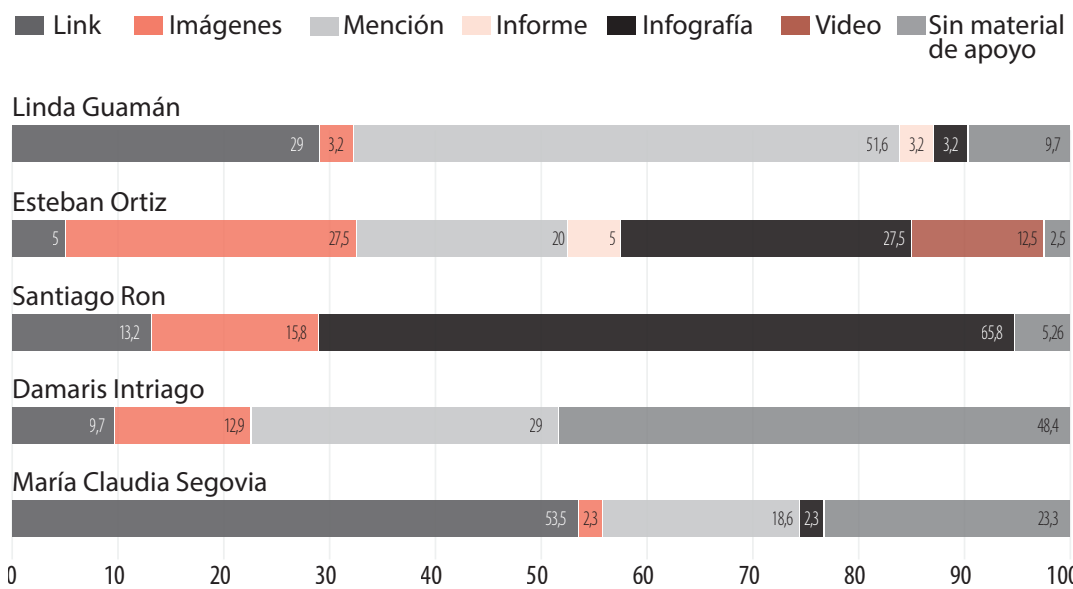

Figura 8. Tweets de Linda Guamán, Esteban Ortiz, Santiago Ron, Damaris Intriago y María Claudia Segovia en abril de 2020 clasificados por el material de apoyo utilizado.

Linda Guamán

Del mismo grupo de tweets analizados, se determinó que la mayoría aplicó menciones como material de apoyo con un 51,6\%. Guamán presentó un $29 \%$ en la utilización de enlaces y el 9,7 \% de sus tweets no contó con material de apoyo. El empleo de infografías, informes e imágenes coincidió en un 3,2 \% para todas las categorías. El uso de material de apoyo permite a las y los investigadores sustentar afirmaciones científicas, para que el contenido del tweet no se quede en una opinión. Cada participante en Twitter tiene una audiencia imaginaria, y su interacción depende con quien se habla y hacia dónde está llevando la conversación (Smith, 2015). Para Guamán (2020), "Twitter es la forma más rápida para llegar a la audiencia que quiero llegar". En este caso la investigadora utiliza mayoritariamente las menciones para incluir en las conversaciones a más usuarios con quienes comparte las temáticas de las que está hablando, lo cual puede considerarse un interesante proceso de networking.

Esteban Ortiz

Ortiz aplicó el uso de imágenes (27,5 \%) e infografías (27,5 \%) en su mayoría. Empleó menciones (20\%), videos (12,5\%), enlaces (5\%), informes (5\%). El $2,5 \%$ de su contenido no disponía de material de apoyo. El uso de imágenes e infografías en una red social fortalece la lectura visual y la interpretación de información científica y datos que pueden resultar complejos para usuarios que no se encuentren en un contexto científico. En este caso, el investigador identifica una función específica en Twitter, como medio de divulgación de 
información rigurosa que requiere ser presentada, porque, aunque la plataforma tiene la misma función, generar contenidos sobre temáticas de actualidad (Guerrero- Pico y Scolari, 2016), los resultados dependen de las acciones que realizan los usuarios según la finalidad que persigan (Parselis, 2014).

\section{Santiago Ron}

Ron dispuso de infografías (65,8 \%), imágenes (15.8\%), enlaces (13,2 \%) y el 5,3\% de sus publicaciones carecían de material de apoyo. El porcentaje de uso de recursos gráficos es muy importante para el investigador, sobre todo porque el discurso que ha compartido en esta red social durante la pandemia ha sido eminentemente técnico para contrarrestar las cifras oficiales con nuevos datos y cálculos. El artefacto (Twitter) es el mismo, lo que va cambiando son las técnicas y habilidades arbitradas por los usuarios y son comunes para todas las finalidades sociales (Parselis, 2014). Ron (2020) considera que los mensajes de Twitter deben ir acompañados de fuentes, sino es muy difícil saber si algo es confiable o no, lo que hace que los posts tengan mayor credibilidad e impacto en el público que se va consolidando dentro de la red.

\section{Damaris Intriago}

El 48,4 \% de las publicaciones de Intriago no contaron con material de apoyo. El $29 \%$ aplicó menciones a otros usuarios, el $12 \%$ corresponde a imágenes y el $9,7 \%$ a enlaces. A diferencia de los otros usuarios analizados, la investigadora tiene un porcentaje alto de tweets sin material de apoyo, su discurso está basado en el texto del cuerpo del tweet. Intriago (2020) menciona que no usa imágenes porque, a veces, le resulta difícil encontrar noticias redactadas de forma divulgativa, por lo que elabora una minireseña. Sin embargo, se evidencia un porcentaje mediado del uso de menciones en la red, acoplando la función de Twitter para crear comunidades de usuarios sobre temáticas dentro de un sistema sociotécnico (Parselis, 2014). El uso de imágenes también refleja interés de Intriago de ver a la red como un espacio abierto para la transformación de la información y la búsqueda de pensamientos disonantes, etc. (Idoiaga, 2016).

\section{Claudia Segovia}

Los enlaces son el material de apoyo más utilizado por Segovia (53,5\%). Le siguen las menciones (18.6\%), las imágenes (2,3\%) e infografías (2,3\%). El $23,3 \%$ de las publicaciones no contaban con material de apoyo. Al igual que los investigadores Ron y Ortiz, Segovia sigue la tendencia de compartir información en Twitter con enlaces de respaldo y menciones, lo que fortalece la imagen informativa con la que se presenta en esta red social, de acuerdo con el análisis previo de los contenidos que más aborda. Twitter tiene una característica de flexibilidad en su función muy amplia, y que no requiere de mayores habilidades operativas para ser utilizado para una finalidad $u$ otra 
(Parselis, 2014), por lo que cada usuario puede darle una finalidad específica de acuerdo con el manejo de construcción de imagen (Moreno, 2020) que quiere proponer en este espacio. Es, además, importante identificar que en Twitter se requiere crear una comunidad para que su uso sea significativo (Parselis, 2014). En el caso de esta investigadora, es la coordinadora de la Red Ecuatoriana de Mujeres Científicas (REMCl) y ha consolidado una comunidad de mujeres investigadoras. Por otro lado, Segovia (2020) manifiesta que comparte artículos interesantes en Twitter que, en su mayoría, se encuentran en inglés, por lo que traduce al menos la introducción y comparte el enlace para lograr el efecto cascada (Sunstein, 2009).

\subsection{Análisis de impacto}

Con las herramientas previas se ha analizado el discurso, el contexto y los contenidos de los tweets de cada uno de los usuarios científicos seleccionados. En esta parte, se realizará el análisis de impacto de aquellos publicados durante los tres primeros meses de la pandemia en Ecuador (abril, mayo y junio) utilizando la herramienta Twitonomy para identificar el alcance de las cuentas estudiadas y la creación de comunidades sobre las diferentes temáticas científicas.

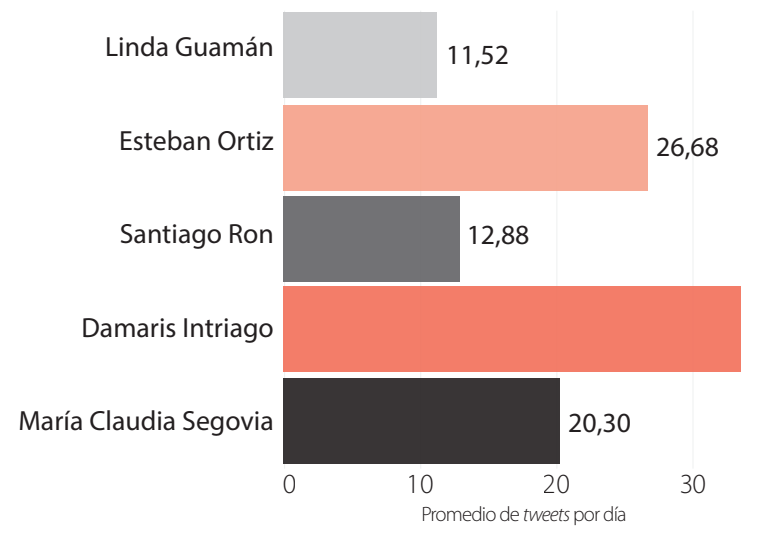

40

Figura 9. Promedio de publicaciones por día. Elaboración propia. Fuente: Twitonomy

La actividad de los usuarios analizados por número de tweets es parecida. Esteban Ortiz, Damaris Intriago y María Claudia Segovia mantuvieron un promedio entre los 20 a los 35 tweets diarios. Mientras que Linda Guamán y Santiago Ron compartieron de 12 a 13 publicaciones. El número de tweets que las fuentes analizadas durante este trimestre determinan su presencia diaria en la red social. La construcción más frecuente de tweets es la noción de participación pública (Smith, 2015) con ideas estrechamente relacionadas que van desde la "sensibilización"y "comprensión", hasta la traducción de la investigación cientí- 
fica, informar o inspirar, por parte de las y los investigadores en Twitter.

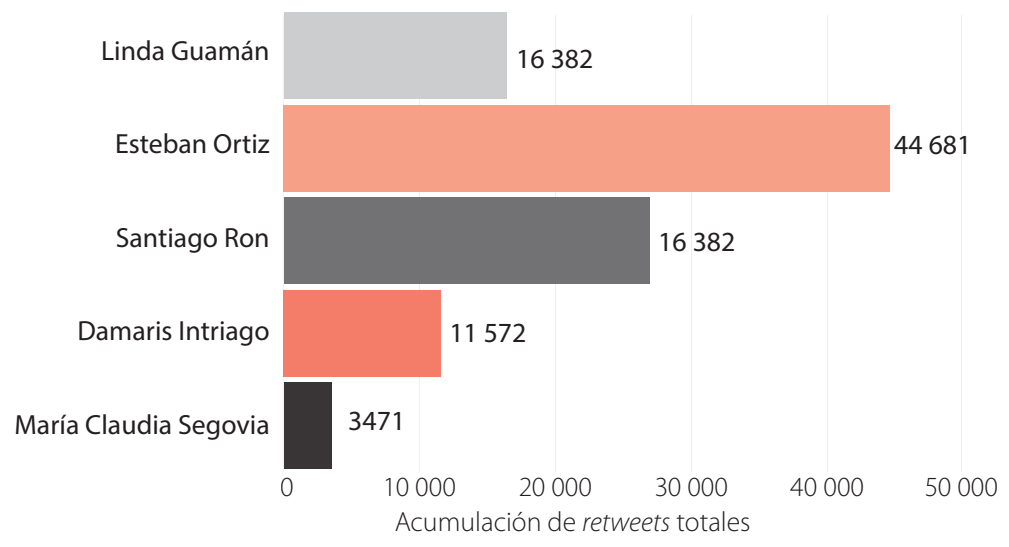

Figura 10. Acumulación de retweets de abril a junio. Elaboración propia. Fuente: Twitonomy

Según Twitonomy, la acumulación de retweets y likes de otros usuarios a las cuentas analizadas indican que estas son fuentes valiosas de información para sus seguidores. También demostraría la afinidad hacia las ideas publicadas en la red social. Con 44681 retweets acumulados entre el mes de abril y junio, Esteban Ortiz es el científico con mayor alcance y conectividad con su audiencia. En segundo lugar, se encuentra Santiago Ron (27 011) y le sigue Linda Guamán (16 382). María Claudia Segovia (3471) es la que menos republicaciones consiguió durante los tres meses estudiados en comparación con sus colegas. Desde el punto de vista sistémico, el vínculo es fundamental debido a que los sistemas se constituyen como tales solo a partir de vínculos fuertes entre sus componentes (Bunge, 2003, citado en Parselis, 2014). En este sentido, las y los científicos han creado vínculos fuertes con su comunidad para generar engagement con su discurso científico (Smith, 2015).

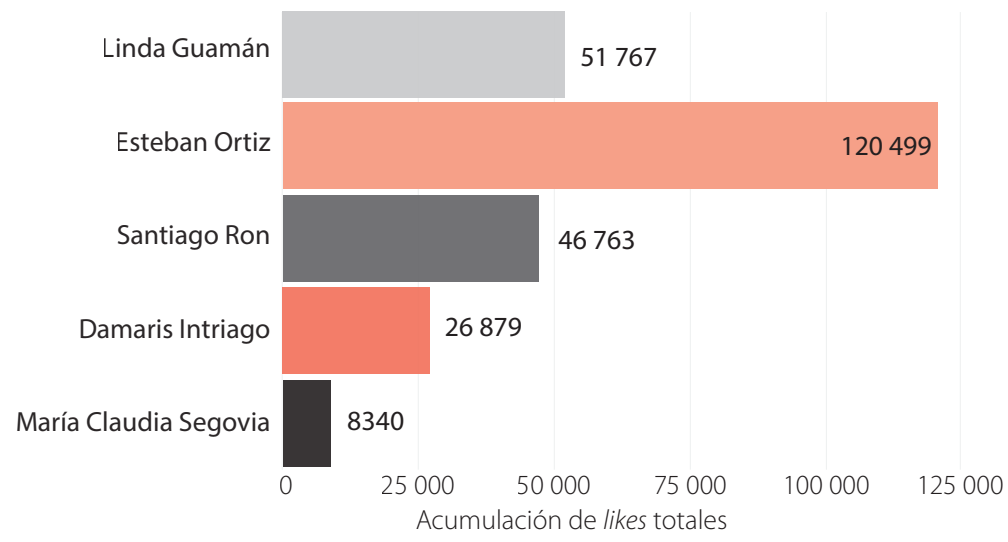


Figura 11. Acumulación de likes de abril a junio. Elaboración propia. Fuente: Twitonomy

Esteban Ortiz (120 499) se mantuvo en primer lugar con los likes de su audiencia. Linda Guamán (51 767) pasó al segundo lugar y Santiago Ron (46 763) al tercero en comparación con los reposteos. María Claudia Segovia (8340) sigue siendo la que menor likes recolecta de sus seguidores. Sin embargo, es importante considerar que este dato se mantiene de acuerdo al número de seguidores que los usuarios mantienen en Twitter. Y eso dependerá de la construcción de comunidades en la red (Parselis, 2014). La generación de las comunidades requiere que las y los científicos conceptualicen al público de una forma diferentes (Smith, 2015), por ejemplo, que lo identifiquen como un conjunto de actores interesados en aprender sobre contenidos de ciencia, en su propio lenguaje y con ejemplos de su cotidianidad.

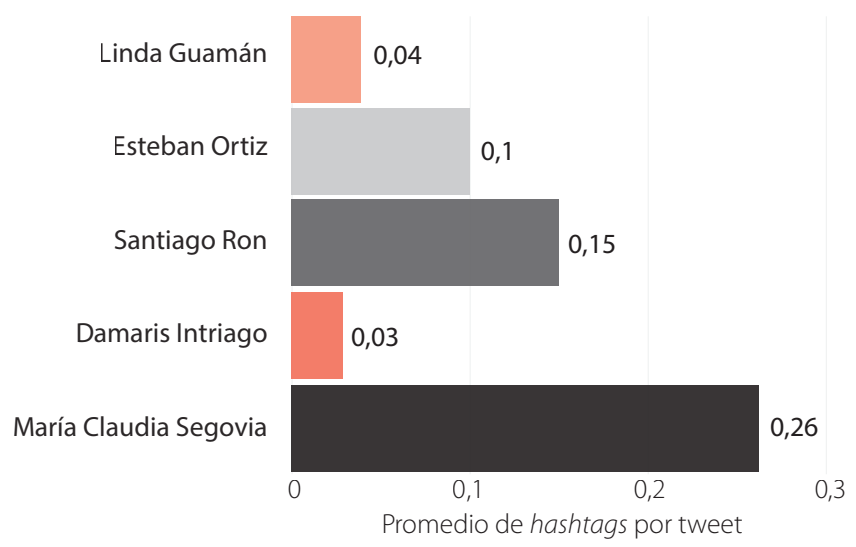

Figura 12. Promedio de hashtags por tweet. Elaboración propia. Fuente: Twitonomy

María Claudia Segovia es la que más utiliza hashtags por cada una de sus publicaciones con un promedio de 0,26. Santiago Ron le sigue con 0,15 hashtags por cada tweet. Parecido al promedio de Esteban Ortiz, 0,10 hashtags por publicación. Linda Guamán $(0,04)$ y Damaris Intriago $(0.03)$ están en penúltimo y último lugar. En la Figura 13 se detallan los hashtags publicados por las cuentas analizadas. El hashtag expresa la actitud del hablante hacia la otra parte de la frase, completando la información proporcionada por esa y desempeñando un papel dialógico (Candale, 2017), una forma de identificar todos los tweets que se están produciendo sobre esa temática. 


\begin{tabular}{c|c} 
Esteban Ortiz & $\begin{array}{r}\text { \#covid19 \#sarscov2 \#portusalud \#quedateencasa } \\
\text { \#sarcasmoavanzado \#covid19ec \#saludoscordiales } \\
\text { \#blacklivesmatter \#unidosporecuador \#frecuenciamedica }\end{array}$ \\
\hline Linda Guamán & $\begin{array}{r}\text { \#sarscov2 \#covid19 \#covid19quito \#saludquito \#covid_19 } \\
\text { \#pseudociencia \#manel \#academiaunida \#sars_cov_2 } \\
\text { \#noalrecorteuniversitario }\end{array}$ \\
\hline Santiago Ron & $\begin{array}{r}\text { \#covid19ec \#coronavirusenecuador \#coronavirusecuador } \\
\text { \#quito \#covid_19ec \#covid_19 \#covid19ecuador } \\
\text { \#coronavirusec \#biodiversidad \#coronavirus }\end{array}$ \\
\hline Intriago & $\begin{array}{r}\text { \#lapseudocienciamata \#sinciencianohayfuturo } \\
\text { \#ecuadornecesitaciencia \#informenación2020 }\end{array}$ \\
\#mibecasinpalanca \#pseudocienciaquemata \#covid19ec \\
\#alertapseudociencia \#dióxidodecloro \#webinar
\end{tabular}

Figura 13. Hashtags más utilizados por cada cuenta. Elaboración propia. Fuente: Twitonomy

Durante el auge de la pandemia de COVID-19 aparecieron varios hashtags en Twitter para identificar la información que se compartía sobre el auge de la crisis sanitaria en el ámbito local, nacional e internacional. Aunque el principal tipo de información que se produce en Twitter corresponde a temas de interés humano: entretenimiento y cultura, tecnología e Internet, y recreación (González Bustamante, 2015), la política está inmersa (Moreno, 2020) y durante la crisis sanitaria mundial se posicionaron las temáticas científicas, para cumplir la función social.

La función propia de Twitter, red social acoplada a una comunidad en un momento dado, está definida colectivamente (Parselis, 2014). En el caso de esta investigación se evidencia que la comunidad científica la usó como una fuente idónea para posicionarse en la opinión pública, divulgar sus conocimientos y generar engagement (Smith, 2015) entre las comunidades de usuarios que empezaron a consolidarse para debatir el discurso oficial.

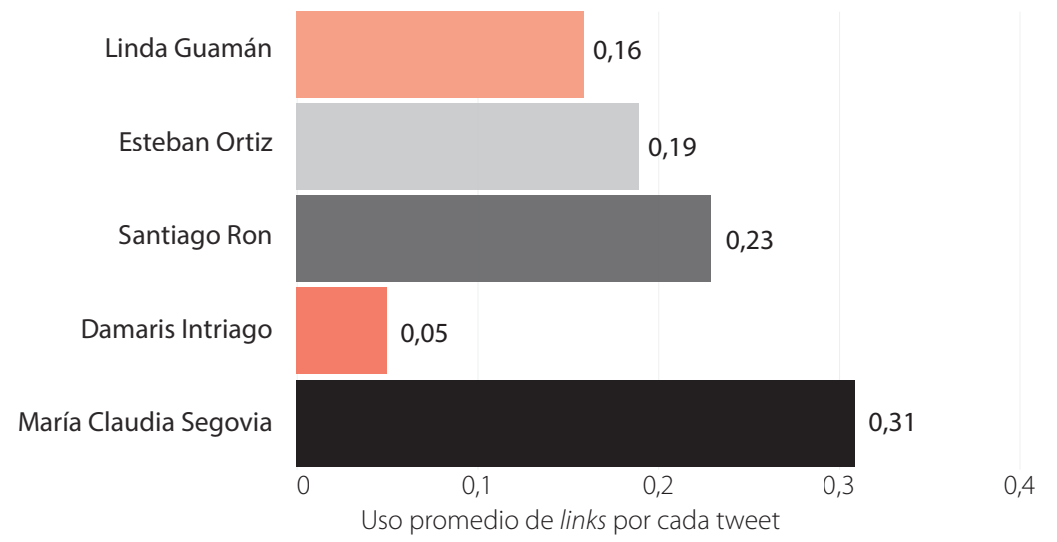


Figura 14. Promedio de uso de enlaces por cada tweet. Elaboración propia. Fuente: Twitonomy

María Claudia Segovia fue la científica que más enlaces utilizó por cada publicación con un promedio de 0,31. Santiago Ron le sigue con 0,23, Esteban Ortiz con 0,19 y Linda Guamán con 0,16. Damaris Intriago fue quien menos enlaces incluyó en sus tweets. La herramienta Twitonomy evidencia lo presentado en el análisis de contenido de los tweets de abril de cada usuario analizado. Para Claudia Segovia es importante compartir enlaces por el tratamiento divulgativo que le dan a esta red social, muy diferente a los resultados que se presentan sobre la investigadora Intriago, quien sigue la tendencia de Twitter como gestora de opinión pública. En términos de información, que es lo que en definitiva desarrolla Twitter, las y los usuarios producen, amplifican, consumen o realizan alguna interacción entre ellos y con la información (Parselis, 2014).

\section{Conclusiones}

El enfoque cuantitativo y cualitativo de esta investigación evidencia que, durante la pandemia de COVID-19 en Ecuador, hay una fuerte presencia del discurso de ciencia en Twitter, pues esta red se utiliza como una plataforma de divulgación científica. Si bien esta no es una tendencia en usuarios de esta plataforma, la muestra permitió analizar que hay un porcentaje de actores de la comunidad científica ecuatoriana que han generado engagement (Smith, 2015) con las comunidades que han creado (Parselis, 2014), utilizando lenguajes comunes para fortalecer el acceso al conocimiento científico. Argumento que se sostiene con lo que considera Guamán (2020): "ser ahora investigador es muy diferente, porque hay un traslado del laboratorio o la universidad, a un campo público en donde si la ciencia no se comunica no sirve".

El contexto que actualmente vive el mundo ha generado y fortalecido la credibilidad de las y los científicos (Van Dijk, 1999) por parte de las comunidades perceptoras, que se que se identifican con el conocimiento socialmente compartido sobre la pandemia, y le dan un uso significativo (Parselis, 2014). Además, se evidencia que los actores de la comunidad científica encuentran en Twitter un espacio para mantener una posición crítica a las cifras oficiales presentadas por el gobierno.

En el análisis de contenidos se evidencian dos tendencias: por un lado, informativa para compartir noticias, datos, cifras y conocimientos sobre el coronavirus y la enfermedad de COVID-19 y, por otro lado, una postura de opinión, lo que indica la tendencia de Twitter a ser una red eminentemente política (Moreno, 2020). El uso de recursos para contextualizar la información marca también una tendencia del uso del artefacto (Parselis, 2014) como un espacio abierto para la transformación de la información y la búsqueda de pensamien- 
tos disonantes, etc. (Idoiaga, 2016).

Las cuentas de las y los científicos seleccionados en esta muestra analizada de la comunidad ecuatoriana demuestran el interés de estos actores por utilizar Twitter como una plataforma de divulgación científica. Sin embargo, esta actividad no es un factor determinante en la formación científica, por lo cual debería ser promovida. Este argumento lo sostiene Intriago (2020) para quien deberían existir cursos que fortalezcan la comunicación de esta comunidad en redes sociales.

Finalmente, se evidencia que los discursos científicos, manejados en un lenguaje divulgativo, por parte de las y los actores analizados en esta investigación, generan impacto en las comunidades de seguidores con quienes interactúan, producen, amplifican y consumen información (Parselis, 2014). El estudio demuestra que las redes sociales pueden convertirse en una excelente plataforma para fomentar el contacto entre la comunidad científica y la sociedad, sobre todo en situaciones de crisis como la coyuntura de la pandemia de COVID-19 


\section{Referencias}

Alonso González, M. (2016). Opinión Pública y web 2.0. Las redes digitalizan el barómetro político en España. Revista Mexicana de Opinión Pública, (21), 95-113. doi: 10.1016/j.rmop.2016.07.004

Avendaño, G., y Arrieta, L. E. (2018). El discurso del tuit: un análisis lingüístico, sociodiscursivo y sociopragmático. Cuadernos de Lingüística Hispánica, (32), 107-130. Recuperado de http://www.scielo.org.co/pdf/clin/n32/0121053X-clin-32-107.pdf

Bauman, Z. (2002). Modernidad Líquida. Buenos Aires: Fondo de Cultura Económica.

Bowater, L. y Yeoman, K. (2012). Science communication: a practical guide for scientists. Chichester: Wiley- Blackwell.

Candale, C. (2017). Las características de las redes sociales y las posibilidades de expresión abiertas por ellas. La comunicación de los jóvenes españoles en Facebook, Twitter e Instagram. Colindancias - Revista de La Red de Hispanistas de Europa Central, (8), 201-220. Recuperado de https://dialnet. unirioja.es/servlet/articulo?codigo $=6319192$

De Vicente Domínguez, A. M. y Cea Esteruelas, N. (2019). El hipertexto en la divulgación científica: análisis de su uso en el perfil de twitter @materia_ ciencia de El País como caso objeto de estudio. Hipertext.Net, (19), 85-92. doi: 10.31009/hipertext.net.2019.i19.07

Del Alcázar Ponce, J. P. (2019). Ecuador Estado Digital Ene/19. Mentinno, (37). Recuperado de https://drive.google.com/file/d/116eZRcn-FH-cLVWmGGlt3jAn_SdG1aTL/view

Dietram, A. y Scheufele, N. M. (2020). How Not to Lose the COVID-19 Communication War. Issues in Science and Technology. Recuperado de https://slate. com/technology/2020/04/covid19-misinformation-science-communication. html

Fernández, M. J., y Paniagua, F. (2012). Representatividad de los emisores en Twitter. Caso de la conversación sobre el anuncio del \#rescate a la banca. Más Poder, (12), 40-48. Recuperado de https://dialnet.unirioja.es/servlet/ articulo? codigo $=4013877$ 
González Bustamante, B. (2015). Evaluando Twitter como indicador de opinión pública: una mirada al arribo de Bachelet a la presidencial chilena 2013. Revista SAAP. Publicación de Ciencia Política de La Sociedad Argentina de Análisis Político, 9(1), 119-141. Recuperado de https://www.redalyc.org/ articulo.oa?id=3871/387142733006

González, M. A. (2016). Opinión pública y web 2.0. Las redes digitalizan el barómetro político en España. Revista Mexicana de Opinión Pública, 21, 95- 113.

Guamán, L. (15 de septiembre de 2020). Uso de Twitter como plataforma de divulgación científica. (S. Cabrera, Entrevistador)

Idoiaga, N. (2016). Redes sociales en tiempos de riesgo: Analizando el ébola mediante twitter. Opción, 32(11), 740-756. Recuperado de http://www. redalyc.org/html/310/31048902043/

Intriago, D. (11 de septiembre de 2020). Uso de Twitter como plataforma de divulgación científica. (C. Clavijo, Entrevistador)

Moreno, G. (10 de septiembre de 2020). Impacto de las redes sociales durante la pandemia en Ecuador. (S. Cabrera, Entrevistador)

Muñoz, A., y Argüelles Álvarez, I. (2010). Análisis del discurso en redes sociales. Twitter un caso bajo estudio. Analizar Datos > Describir Variación, 1, 64. Recuperado de http://dialnet.unirioja.es/servlet/extart?codigo=3411103

Ortiz, E. (15 de septiembre de 2020). Uso de Twitter como plataforma de divulgación científica. (C. Clavijo, Entrevistador)

Parselis, M. (2014). Función e innovación social, el caso Twitter Social function and social innovation, the Twitter case. Revista Iberoamericana de Ciencia Tecnología y Sociedad, 9(25), 53-71. Recuperado de http://www.revistacts.net/files/Volumen 9 - Número 25/Parselis_EDITADO.pdf

Pico, M. G., y Scolari, C. (2016). Narrativas transmedia y contenidos generados por los usuarios: el caso de los crossovers. Cuadernos.Info, (38), 183-200. doi: $10.7764 /$ cdi.38.760

Revuelta, G. (19 de mayo de 2020). El día en que los científicos (y científicas) irrumpieron en la arena pública. Blog - Asociación Española de Comunicación Científica. Recuperado de https://www.aecomunicacioncientifica. org/el-dia-en-que-los-cientificos-y-cientificas-irrumpieron-en-la-arenapublica/ 
Ron, S. (10 de septiembre de 2020). Uso de Twitter como plataforma de divulgación científica. (S. Cabrera, Entrevistador)

Santander, P. (2011). Por qué y cómo hacer análisis de discurso. Cinta de Moebio, (41), 207-224. doi:10.4067/s0717-554x2011000200006

Segovia, M. C. (11 de septiembre de 2020). Uso de Twitter como plataforma de divulgación científica. (M. Clavijo, Entrevistador)

Smith, A. (2015). How scientist use twitter for public engagement. Promotionalcommunications.Org. Recuperado de http://promotionalcommunications.org/ind

Sunstain, C. (2009). On rumours, How falsehoods spread, why we believe them, what can be done. Londres: Penguin.

Van Dijk, T. A. (1999). Análisis crítico del discurso. Revista Anthropos, (30), 203222. doi:10.4206/rev.austral.cienc.soc.2016.n30-10 